\title{
Lipid biomarker analysis on the sediments of a lignite-bearing succession
}

\author{
RIMPY CHETIA ${ }^{1,2}$, RUNCIE PAUL MATHEWS ${ }^{1}$ AND \\ PRAKASH K. SINGH ${ }^{2}$ \\ ${ }^{1}$ Birbal Sahni Institute of Palaeosciences \\ ${ }^{2}$ Banaras Hindu University \\ Presenting Author: rimpy.bsrs@bsip.res.in
}

Lipid extracts from lignite bearing succession of Jalipa lignite mine (Rajasthan), western India were analysed by Gas Chromatography- Mass Spectrometry (GC-MS) to trace its floral origin and to understand its general depositional condition. The alkanes and terpenoids in the succession are identified and interpreted. The distribution pattern of various $n$-alkanes and the derived indices/ratios has been widely used as palaeoclimate indicators in several depositional settings. The distribution of $n$ alkanes in the studied sequence varies from $C_{13}$ to $C_{29}$. The values of calculated $n$-alkane parameters range from 1.00-28.66 (aliphatic chain length (ACL) index); 0.65-58.60 (low-to-higher molecular weight $(\mathrm{L} / \mathrm{H})$ ratio); $1.00-27.83$ (Proxy wax $\left(\mathrm{P}_{\mathrm{wax}}\right)$ ); 0.59-1.0. (Proxy aqueous $\left(\mathrm{P}_{\mathrm{aq}}\right)$ ); 0.03-3.10 (terrigenous/aquatic ratio (TAR)). Terpenoids are good source indicators. The terpenoid suite consists of sesquiterpanes with various cadalenes and cadalene-derivatives, curcumenes etc which are vascular plant biogeochemical signatures. The diterpenoid composition is low but a few abietane-derivatives along with some unidentified abietane-class compounds are found which are conifer markers. Various tryclic triterpenoids of bacterial or fungal origin are also identified. The non-hopanoid triterpenoid also include tetracyclic-class sesterterpenoids like de-A-olean-13(18)-ene. Pentacyclic terpenoid compounds include the hopanoids, the oleananes, ursanes and their derivatives. The oleananes and ursanes are also detected in their aromatically derived forms. The hopanes indicates early stages of diagenesis. These indicates the deposit was formed with intermittent changes in climatic conditions and this lignite-bearing sequence formed with a mixed source flora comprising of gymnosperms and angiosperms along with aquatic vegetation, flourishing in a microbially-active realm with a suboxic condition. 